

UC-NRLF

|inininin \$B $34 \quad 493$ 


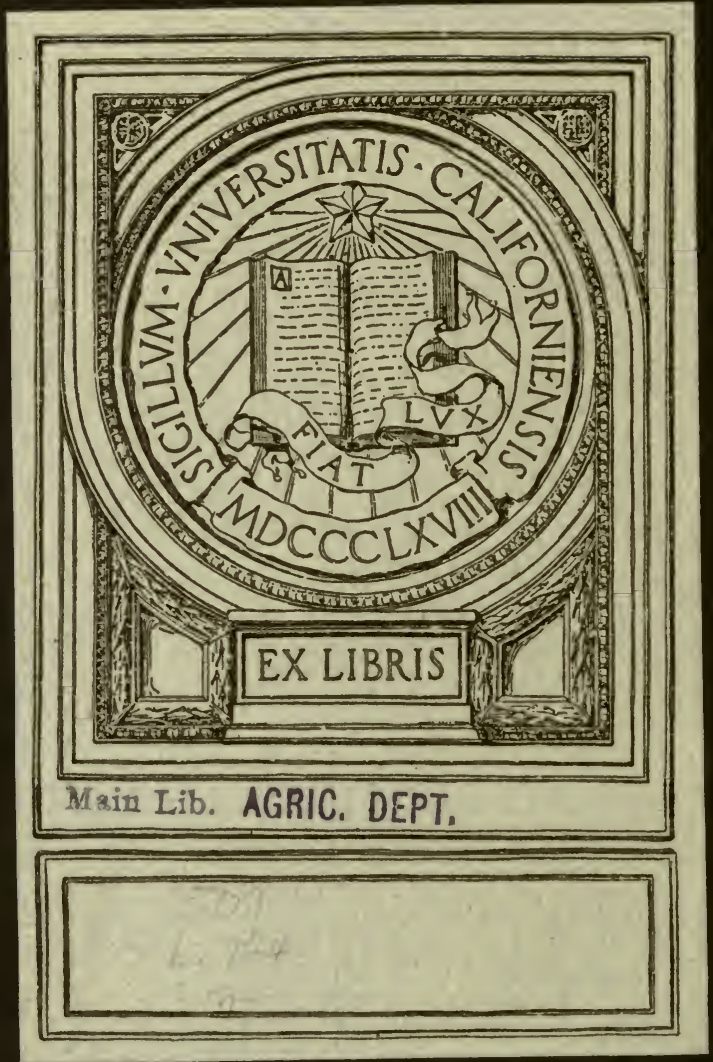




\section{NITROGEN FIXATION BY YEASTS AND OTHER}

\section{FUNGI}

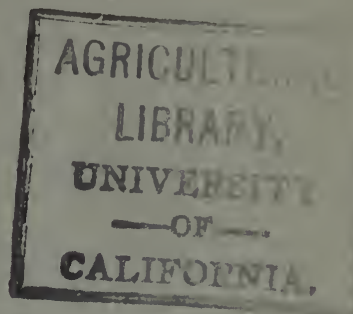

BY

CHARLES B. LIPMAN

(From the Research Laboratory for Soll Chemistry and Bacteriology, University of California)

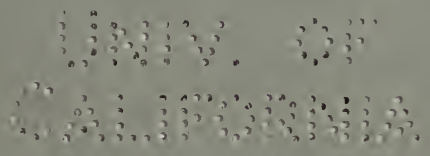

From

JOURNAL OF BIOLOGICAL CHEMISTRY

Vol. X, No. 3, ОстовеR, 1911 
<smiles>[GeH2][AsH2]</smiles>

Aarits 1 i!,

Agric. Je.






\title{
NITROGEN FIXATION BY YEASTS AND OTHER FUNGI.
}

\author{
BY CHARLES B. LIPMAN.
}

(From the Research Laboratory for Soil Chemistry and Bacteriology, Universily of California.)

(Received for publication, July 28, 1911.)

Since the epoch making discoveries of Hellriegel ${ }^{1}$ there have followed in quick succession many series of investigations relative to the fixation of atmospheric nitrogen by living organisms. Especially brilliant are the investigations of Winogradsky ${ }^{2}$ on Clostridium pastorianum and those of Beyerinck ${ }^{3}$ on the Azotobacter group, and it is unnecessary here to go into a review of the investigations which have since added themselves to those, for the reader is doubtless acquainted with the painstaking and interesting researches of Gerlach and Vogel, Krüger and Schneidewind, J. G. Lipman, Löhnis, Christensen and a host of others to whom we are indebted for information on the subject of the fixation of atmospheric nitrogen by soil bacteria. Suffice it to say, that the researches of the past twenty-five years have disclosed facts which point emphatically toward the conclusion that the earth is endowed with agencies which, at least in part, compensate for the losses from our valuable nitrogen store from the soil which are constantly going on. From the earliest of these researches it appeared that the power of living organisms to assimilate atmospheric nitrogen was limited to a small group of bacteria of which the power seemed as characteristic and distinct as did the power of the group of nitrifying bacteria to change ammonium compounds to nitrates, but the later investigations soon brought to light the fact that many bacteria other than those of the $B$. radicicola, the Azotobacter and the Clostridium groups exhibited the power, more or less pronounced, of fixing atmospheric nitro- .

${ }^{1}$ Ueber die Stickstoffnährung der Gramineen und Leguminosen, 1888.

${ }^{2}$ Compt. rend. de l'Acad. des Sci., 1893.

${ }^{3}$ Centralbl. f. Bakt., ix, 2 Abt., p. 3, 1902.

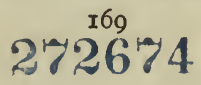


gen. These discoveries led further to a study of other organisms belonging to the groups of yeasts, molds and the higher fungi, in a search for those among them which possessed the peculiar physiological power to fix atmospheric nitrogen. These studies have resulted in both positive and negative results frequently with the same organisms in the hands of different investigators, and the present status of the question is still unsettled pending further evidence of the definite and constant powers of the fungi mentioned to fix atmospheric nitrogen. It was therefore with the double intention of making a further contribution to our knowledge of the nitrogen fixing powers of some of the organisms already studied as well as the study in that direction of organisms which until now, so far as the writer is aware, have not been experimented with, that the subjoined investigations were undertaken. It was decided to make a study of the nitrogen fixing powers of some of the true yeasts, "pseudo-yeasts,"1 Mycoderma varieties and some of the common molds, among them Aspergillus niger, Penicillium glaucum, Botrytis cinerea and others. Before, however, going into the detailed description of the experiments carried out it will be helpful for purposes of comparison to review briefly the several researches, which have been carried out on the nitrogen fixing powers of organisms which are the same or similar to those employed in my experiments.

The investigations of Jodin ${ }^{2}$ and Hallier ${ }^{3}$ carried out as early as the sixties of the last century led them to believe that fungi were possessed of the power to fix nitrogen. Their results and opinions on this matter were not confirmed, however by Woff and Zimmerman. ${ }^{4}$

Sestini and del Torre reported some investigations in 1876 which seemed to have a doubtful significance. In their communication they make mention, however, of a statement by Selmi in which the latter attributes to the Mycoderma forms the power to produce ammonia from atmospheric nitrogen in the presence of nascent hydrogen.

${ }^{1}$ A term employed by zymologists to designate the yeast-like organisms which do not form spores.

${ }^{2}$ Compt. rend. de l'Acad. des Sci., lv, p. 612.

${ }^{3}$ Zeitschr. f. Parasitenkunde, i, p. 129.

"Abstract in Jahresbericht der Agrikultur Chemie, xiii-xv, p. 169 
The investigations of Loew and Nageli ${ }^{1}$ led them to make the statement that elementary nitrogen is an unsatisfactory source of that element for molds. Lawes, Gilbert and Warrington ${ }^{2}$ could not show any fixation of nitrogen by some soil molds since analyses of soil, in which these molds were, showed no increase of nitrogen.

Winogradsky has reported negative results in experiments with an Aspergillus species, and Czapek ${ }^{3}$ has likewise reported negative results with Aspergillus niger and criticised the results of Puriewitsch and Saida, especially the latter, on the ground that the amounts of nitrogen fixed may have been due to errors in the nitrogen determinations. Gerlach and $V_{0} \mathrm{ge}^{4}$ reported negative results with a yeast experimented with by them.

To all of these doubtful or negative results on the fixation of nitrogen by yeasts, molds and other fungi, should be added the results of investigations very recently carried out by Duggar and Knudson $^{5}$ at Cornell University in which it is claimed that no nitrogen fixation was observed, except to a very slight extent in cultures of Aspergillus niger.

Opposed to these negative results we have the positive results of several investigators in which we find a description of marked powers of fixing nitrogen attributed to the yeasts and molds experimented with. Berthelot ${ }^{6}$ noted gains of nitrogen in cultures of Aspergillus niger, Alternaria tenuis and Gymnoascus, but only the cultures of Alternaria tenuis were pure. Puriewitsch, ${ }^{7}$ however, worked with pure cultures of Aspergillus niger and Penicillium glaucum and in addition to all other precautions to exclude bacteria from these cultures he added some phosphoric acid to his culture solution which latter consisted of 100 cc. of water, 0.4 gram of monopotassium phosphate, 0.4 gram of calcium chloride, 0.2 gram of magnesium sulphate, 3 grams of tartaric acid, varying amounts of dextrose and small amounts of ammonium nitrate.

${ }^{1}$ Sitzungsber. d. mathem. physik. Klasse d. Akad. München, x, p. 280.

'Journ. Chem. Society, Transactions, xliii, p. 208.

${ }^{3}$ Beitr. z. chem. Physiol. und Pathol., ii, p. 559, 1902.

'Loc. cit.

'Abstract in Science, Feb. 3, 1911, of a paper read before the Botanical Society of America.

${ }^{6}$ Chimie vegetale et agricole, i, Paris, 1899.

${ }^{7}$ Ber. d. deutsch. bot. Ges., xiii, p. 339, 1895. 
Gains of nitrogen were noted in all cultures. It is interesting however, to observe in his results, the large differences in the amounts of nitrogen fixed by the same organism in duplicate cultures. Saida ${ }^{1}$ not only confirmed the results of Puriewitsch on Aspergillus niger, but showed that a distinct nitrogen fixing power was possessed by Mucor stolonifer, Endococcus purpurascens, and Phoma betae. No gains of nitrogen, however, were noted by the same investigator in cultures of Acrostalagmus cinnibarinus, Monilia variabilis and Fusisporium moschatum. A. Koch ${ }^{2}$ claims that he and other investigators in repeating the experiments of Puriewitsch and Saida could not obtain any fixation of nitrogen, but calls attention to the fact that his results must not be taken as proof of the questionable purity of the cultures used by Puriewitsch and Saida nor yet of any error in the work of the last named investigators but rather to a change in the character of the organisms in old cultures as indeed this has often been noted in cultures of Azotobacter which after long standing seemed to have only a feeble nitrogen fixing power. This is an interesting observation which agrees with a similar one made by the writer in the experiments described below.

Frank $^{3}$ showed distinct gains of nitrogen in work carried out with different species of Penicillium, amounting in one case to $3.5 \mathrm{mg}$. of nitrogen in $65 \mathrm{cc}$. of nitrogen-free sugar solution in an incubation period of ten months. Remy ${ }^{4}$ also showed fixation of nitrogen by three out of twenty-five molds which he tested and among these was Aspergillus niger which fixed $10 \mathrm{mg}$. of nitrogen on 20 grams of dextrose as a source of energy. To these must also be added the investigations of Ternet ${ }^{5}$ who found in working with five species of Phoma that the latter possessed a pronounced nitrogen fixing power, noting in one case a fixation of $22 \mathrm{mg}$. of nitrogen per gram of dextrose. The same investigator noted gains of nitrogen also in cultures of Penicillium glaucum and Aspergillus niger amounting in the latter case to $2.71 \mathrm{mg}$. nitrogen per gram of dextrose.

${ }^{1}$ Ber. d. deutsch. bot. Ges., xix, p. 107, 1901.

${ }^{2}$ Handbuch der technischen Mykologie, Jena, iii, 1907.

${ }^{3}$ Landw. Jahrb., xxi, p. 7, 1892; Bot. Zeitung, li, p. 146, 1893.

"Verh. d. Ges. deutsch. Naturf. und Aerzte, lxxiv, i, p. 221, 1902.

${ }^{5}$ Ber. d. deutsch. bot. Ges., xxii, p. 267; Jahrb. f. wissen. Botanik, xliv, 1907 , p. $353-408$. 
Gains of nitrogen were also noted by Heinze ${ }^{1}$ in cultures of yeasts in their spore forming stages and in cultures of lichens in the gonidium form. There should also be mentioned here the experiments of Gerlach and Vogel ${ }^{2}$ in which they found a mold to possess the power of increasing the nitrogen content of the culture from $2.8 \mathrm{mg}$. to $5.1 \mathrm{mg}$. This increase is attributed by Gerlach and Vogel to experimental error, but, as Löhnis well remarks in reviewing this matter, the other data given in the same investigations do not support such a view.

In a series of very carefully conducted experiments in which every possible precaution was taken to prevent absorption of ammonia and amido compounds from the air by the culture solutions, Fröhlich ${ }^{3}$ showed very considerable and definite gains of nitrogen in cultures of fungi obtained from their growths on dead parts of plants. These fungi belonged to the hyphomycetes, and one of them Macrosporium commune fixed on the average as much as $8.92 \mathrm{mg}$. of nitrogen per gram of dextrose used. In addition to these results the same investigator confirmed the results of others above noted with respect to the nitrogen fixing powers of Penicillium glaucum and Aspergillus niger. Latham ${ }^{4}$ further confirms the results of Berthelot, Puriewitsch, Saida, Remy, Ternetz, Fröhlich and others above mentioned, in his experiments with Aspergillus niger.

Of particular interest in connection with the writer's results are those of Zikes ${ }^{5}$ who describes a torula form, isolated from laurel leaves and named by him Torula wiesneri which possesses a power of nitrogen fixation equal to 2.3 to $2.4 \mathrm{mg}$. per gram of glucose used. The experiments of Löhnis and Pillai ${ }^{6}$ show only a slight nitrogen fixing power for a torula form employed by them, but a larger fixation of nitrogen by Dematium pullulans.

${ }^{1}$ Centralbl. f. Bakt., x, 2 Abt., p. 675 ; xii, p. 357.

'Beitr. z. chem. Physiol. u. Path., ii, 1907.

'Jahrb. f. wissen. Botanik, xlv, p. 256, 1907.

'Bull. Torrey Bot. Club, xxxvi, p. 235, 1909.

'Sitzungsber. Akad. Wien, math-naturw. Kl., cxviii, p. 1091.

${ }^{6}$ Lohnis and Pillai: Centralbl. f. Bakt., xx, 2 Abt., p. 799. 
EXPERIMENTAL.

The material tested in these experiments consisted of seven species of saccharomyces, six varieties of "pseudo-yeasts," one mycoderma (Mycoderma vini) and three molds. The cultures employed were kindly given to the writer by Prof. F. T. Bioletti of the California Agricultural Experiment Station to whom I desire, here, to express my sincere thanks. The cultures were all examined microscopically and appeared to be pure cultures of the organisms named in the tables.

\section{Series $I$.}

A culture solution ${ }^{2}$ was prepared and distributed in 100 cc. portions in $500 \mathrm{cc}$. Erlenmeyer flasks and sterilized in the autoclave. Each liter of solution consisted of the following:

15.0 grams mannite.

0.2 gram dipotassium phosphate.

0.2 gram magnesium sulphate.

0.02 gram calcium chloride.

3 drops of a 10 per cent solution of ferric chloride. 1000 cc. tap water.

The solution was rendered slightly alkaline to phenolphthalein by means of sodium hydrate. The solutions were carefully inoculated to prevent contamination, by means of a sterile platinum loop and placed in the incubator at $26^{\circ}-28^{\circ} \mathrm{C}$. for one month, after which they were transferred to Kjeldahl digestion flasks, 30 cc. concentrated sulphuric acid added and boiled on the digestion shelf until frothing ceased ${ }^{3}$; then about 12 grams of a mixture of $\mathrm{K}_{2} \mathrm{SO}_{4}, \mathrm{FeSO}_{4}$ and $\mathrm{CuSO}_{4}$ (in the proportion of 10 to 1 to $\frac{1}{2}$ ) were added and the digestion continued for another hour or more. When cool the digested solutions were transferred to copper distilling

${ }^{1}$ These organisms are described by Holm: Bull. No. 197, Cal. Expt. Station.

${ }^{2}$ Used by Lipman and Brown: New Jersey Agr. Expt. Station, Bulletin No. 210.

${ }^{3}$ The method for the nitrogen determination used is given in detail because it presents some new modifications which allow of rapid and accurate work, as shown by tests in experiments which will be published shortly. 
flasks, diluted to proper volume, an excess of lye added, also some powdered zinc to prevent bumping and the ammonia dis-' tilling over was caught in $\frac{\mathrm{N}}{10} \mathrm{HCl}$. The excess of the latter was titrated against $\frac{\mathrm{N}}{10} \mathrm{NH}_{4} \mathrm{OH}$; and the amount of nitrogen fixed calculated in milligrams. Several sterile controls were run with each series. The results of the first series follow:

TABLE I.

\begin{tabular}{|c|c|c|c|}
\hline No. & NAME & $\begin{array}{l}\text { NITROGEN } \\
\text { FOUND }\end{array}$ & $\begin{array}{l}\text { NITROGEN } \\
\text { FIXED }\end{array}$ \\
\hline & & $m g$. & $m g$. \\
\hline 1 & 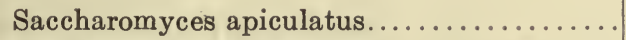 & 1.75 & 0.84 \\
\hline 2 & Saccharomyces ellipsoideus, champagne.... & 1.87 & 0.96 \\
\hline 3 & Saccharomyces cerevisioe, carlsbergensis. . & 1.87 & 0.96 \\
\hline 4 & Saccharomyces ellipsoideus, Steinberg..... & 1.09 & 0.18 \\
\hline 5 & Saccharomyces cerevisioe, Distillery $R_{2} \ldots$ & 1.04 & 0.13 \\
\hline 6 & Saccharomyces ellipsoideus, Bioletti........ & 1.01 & 0.10 \\
\hline 7 & 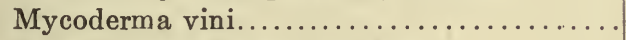 & 1.40 & 0.49 \\
\hline 8 & Pseudo yeast, Tulare No. $46 \mathrm{a} \ldots \ldots \ldots \ldots \ldots$ & 1.26 & 0.35 \\
\hline 9 & Pseudo yeast, Tulare No. 46b.......... & 2.38 & 1.47 \\
\hline 10 & Pseudo yeast, Tulare No. $45 \mathrm{~b}$. & 0.91 & 0.00 \\
\hline 11 & Pseudo yeast, Tulare No. $28 \mathrm{a} . .$. . & 1.12 & 0.21 \\
\hline 12 & Pseudo yeast, Tulare No. 26 .. & 1.26 & 0.35 \\
\hline 13 & Pseudo yeast, Tulare No. 37 . & 0.95 & 0.04 \\
\hline 14 & Aspergillus niger ........... & 1.40 & 0.49 \\
\hline
\end{tabular}

Every culture seems to show an increase of nitrogen except nos. 10 and 13 , but it may also be probable that the amounts fixed in nos. 4, 5, 6 and 11 may lie within the limits of error, and possibly even nos. 8 and 12 may be included in this list. Nevertheless, there is a distinct fixation of nitrogen in nos. 1, 2, 3, 7, 9 and 14, or in six out of fourteen cultures, and it is interesting to note that of these six, three are true yeasts, one a mycoderma, one a pseudo yeast and one a mold. The largest amount fixed in this series was that in no. 9 by the "pseudo yeast" called Tulare no. $46 \mathrm{~b}$.

It would seem therefore that these results are a further confirmation of those of Saida, Puriewitsch, Ternetz, Fröhlich, Zikes and others above mentioned, and it is especially interesting to note that the organism in the series above given which showed the largest fixation of nitrogen is very much like the Torula wiesneri 
with which Zikes worked and which fixed considerably more nitrogen.

That fixation should further have taken place in cultures representing the various classes of organisms experimented with, confirms the writer in the belief which he has held ever since these investigations were begun that the power of fixing atmospheric nitrogen though perhaps not a universal one among the lower plants is yet a very widespread power among the fungi. The fixation of nitrogen by true yeasts is, so far as the writer is aware, the first one described as such in the literature on the subject and adds another class of organisms to the now rapidly growing list of those which seem to be possessed of that power. It must also be mentioned here that the culture solution used above while a very good one for organisms of the Azotobacter group is not necessarily a satisfactory one for the organisms studied and was only employed because of the fact that so many different organisms were used and further obviously that no information is available as to what constitutes a good medium for nitrogen fixation for each class of organisms tested. It is possible, for example, that the alkaline reaction of the culture solution which is so necessary to the fixation of nitrogen by Azotobacter may be rather a hindrance than otherwise to the nitrogen fixing powers of Aspergillus niger or even the yeasts. Despite that, however, we have evidence of a power of nitrogen fixation, more or less pronounced, in each of these classes of organisms.

\section{Series II.}

Owing to the fact that the zymologist values dextrose so highly as a medium for fermentation by yeasts, it was decided to arrange a series like the preceding but to substitute dextrose for mannite. The solutions were distributed in $100 \mathrm{cc}$. portions in $500 \mathrm{cc}$. Erlenmeyer flasks as described in the first series, and after the requisite sterilization and cooling were inoculated from the beer wort cultures of the organisms tested. The incubationwas carried out in the same manner as in the preceding series, after which the solutions were analyzed for nitrogen according to the modification of the Kjeldahl method above described. The results of the analyses follow: 
TABLE II.

\begin{tabular}{|c|c|c|c|}
\hline No. & NAME & $\begin{array}{l}\text { NITROGEN } \\
\text { FOUND }\end{array}$ & $\begin{array}{l}\text { NITROGEN } \\
\text { FIXED }\end{array}$ \\
\hline & & $m g$. & $m g$. \\
\hline 1 & Saccharomyces apiculatus....... & 3.37 & 0.92 \\
\hline 2 & Saccharomyces ellipsoideus, champagne. & 2.69 & 0.24 \\
\hline 3 & Saccharomyces cerevisioe, carlsbergensis... & 4.19 & 1.74 \\
\hline 4 & Saccharomyces ellipsoideus, Steinberg... & 3.43 & 0.98 \\
\hline 5 & Saccharomyces cerevisioe, Distillery $R_{2} \ldots$ & 3.99 & 1.54 \\
\hline 6. & Saccharomyces ellipsoideus, Bioletti.... & 2.63 & 0.18 \\
\hline 7 & Saccharomyces ellipsoideus, Burgundy... & 2.59 & 0.14 \\
\hline 8 & 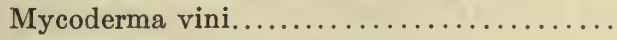 & 4.24 & 1.79 \\
\hline 9 & Pseudo yeast, Tulare No. 46a.......... & 4.73 & 2.28 \\
\hline 10 & Pseudo yeast, Tulare No. $46 \mathrm{~b} \ldots . .$. . & 3.71 & 1.26 \\
\hline 11 & Pseudo yeast, Tulare No. $45 \mathrm{~b} .$. & 2.52 & 0.07 \\
\hline 12 & Pseudo yeast, Tulare No. 28a... . & 4.54 & 2.09 \\
\hline 13 & Pseudo yeast, Tulare No. 26 . & 3.50 & 1.05 \\
\hline 14 & Aspergillus niger............ & 4.68 & 2.23 \\
\hline 15 & Penicillium glaucum..... .. & 3.15 & 1.70 \\
\hline
\end{tabular}

A glance at Table II shows the influence of the kind of medium on the amount of nitrogen fixed. Not only does dextrose allow of a much larger fixation of nitrogen by the same organisms which showed fixation in mannite solutions but it allows other organisms to fix nitrogen which showed but a small nitrogen fixing power or none at all in the other medium. This is a factor which cannot be overlooked in considering the practical phases of nitrogen fixation as related to the nitrogen supply for plants in the universe. Here again, it would appear, the pseudo yeasts are more efficient at nitrogen fixation, when showing that power at all, than the true yeasts. For Aspergillus niger we find dextrose to be far superior to mannite as a source of energy, and we find it to have a power of nitrogen fixation in the medium which corresponds closely to that exhibited by the same organism in the hands of other investigators above mentioned. Penicillium glaucum, too, manifests a definite power of nitrogen fixation in dextrose solutions and this again corresponds to the results obtained by other investigators whose work is above reviewed.

We find thus that at least eleven of the fifteen organisms above tested show more or less pronounced powers of fixing nitrogen. Owing to the higher content of nitrogen in the tap water used at this time and also the higher content of nitrogen in the lye and 
acid used in the nitrogen determinations, we find a much higher blank here, but several blanks were analyzed and the close agreement between them showed the results above given to be trustworthy. It should be mentioned here that the sterile blanks in all these series were not merely analyzed from the original solution but were inoculated like the cultures, then sterilized and incubated side by side with the cultures for the same length of time. It is interesting to note here that the amount of visible growth cannot be directly correlated with the amount of nitrogen fixed, for several of the cultures which appeared to have made only a small amount of growth showed quite a considerable fixation of nitrogen. I presume that this has been observed by other investigators working on this problem and is probably due to the fact that some of the nitrogen compounds produced are soluble and diffusible and therefore give no visible evidence of their presence. It is hardly necessary to add here that despite the favorable constitution of the medium employed it is not nearly so favorable for the growth of the organisms tested as the beer wort in which the stock cultures were kept as can be noticed particularly in the cultures of Aspergillus niger and Penicillium glaucum where the membranes formed in the dextrose solution are very thin and light in color and the spore production much smaller, than in the beer wort cultures.

\section{Series $I I I$.}

As explained above the culture solutions employed in the preceding series were prepared with tap water and the necessary sugar and salts added. It appeared to the writer that a more rigid test of the power to fix nitrogen possessed by the organisms in question should be made. It seemed desirable to see if, like the nitrogen fixing bacteria of the Azotobacter group, they had the power to fix nitrogen in nitrogen-free solutions or solutions which are practically nitrogen-free. It was also thought desirable to test the comparative values of mannite and four of the sugars in such nitrogen-free solutions as sources of energy for the organisms. To that end solutions like the one described above were prepared but distilled water, free from ammonia, was substituted for tap water. The salts employed being chemically pure and used only in small quantities as noted, could not contain more than a trace 
of nitrogen. The sugars employed besides mannite were dextrose, maltose, lactose and saccharose. These were all chemically pure and thus the solutions when made up could only contain traces of combined nitrogen.

A change in the method of preparing the cultures in addition to the above should also be noted here. Twenty, instead of 15 , grams of sugar were added to each liter of solution. The latter was distributed in 50 cc. portions in 250 cc. Erlenmeyer flasks each of which therefore contained 1 gram of mannite or sugar. The inoculations and incubation were carried out as in the preceding series except that the cultures in the maltose, lactose and saccharose solutions were incubated for twenty-five days instead of one month as were all the others. The superior nature of the tap water as compared with the distilled water was seen early in the incubation period. The growth in the distilled water cultures was much slighter and this was particularly noticeable in the case of the molds. The results of the nitrogen determinations follow, all arranged in one table so that the various sugars may be readily compared.

The results in Table III show clearly that every one of the organisms tested possesses a power, more or less marked, of fixing atmospheric nitrogen. In some cases that power seems to be so slight indeed as to be negligible but in most cases it is very distinct and definite. The next striking fact which presents itself for consideration in an examination of the foregoing table is the great difference in the nitrogen fixing power, of the several organisms tested, in the different media. While mannite seems to have been the most favorable source of energy for the largest number of organisms tested, some of the sugars employed allowed of the fixation of nitrogen by organisms which did not fix any nitrogen at all in mannite solutions.

The highest amounts of nitrogen fixed were quite considerable and compare well with the amounts fixed by pure cultures of Clostridium pastorianum and some of the less vigorous species of the Azotobacter group. We find here again in the dextrose and lactose solutions a confirmation of the work of other investigators above mentioned with respect to Aspergillus niger, and in the mannite solutions with respect to Penicillium glaucum. While the amounts fixed are in most cases not as large in these distilled 
TABLE III.

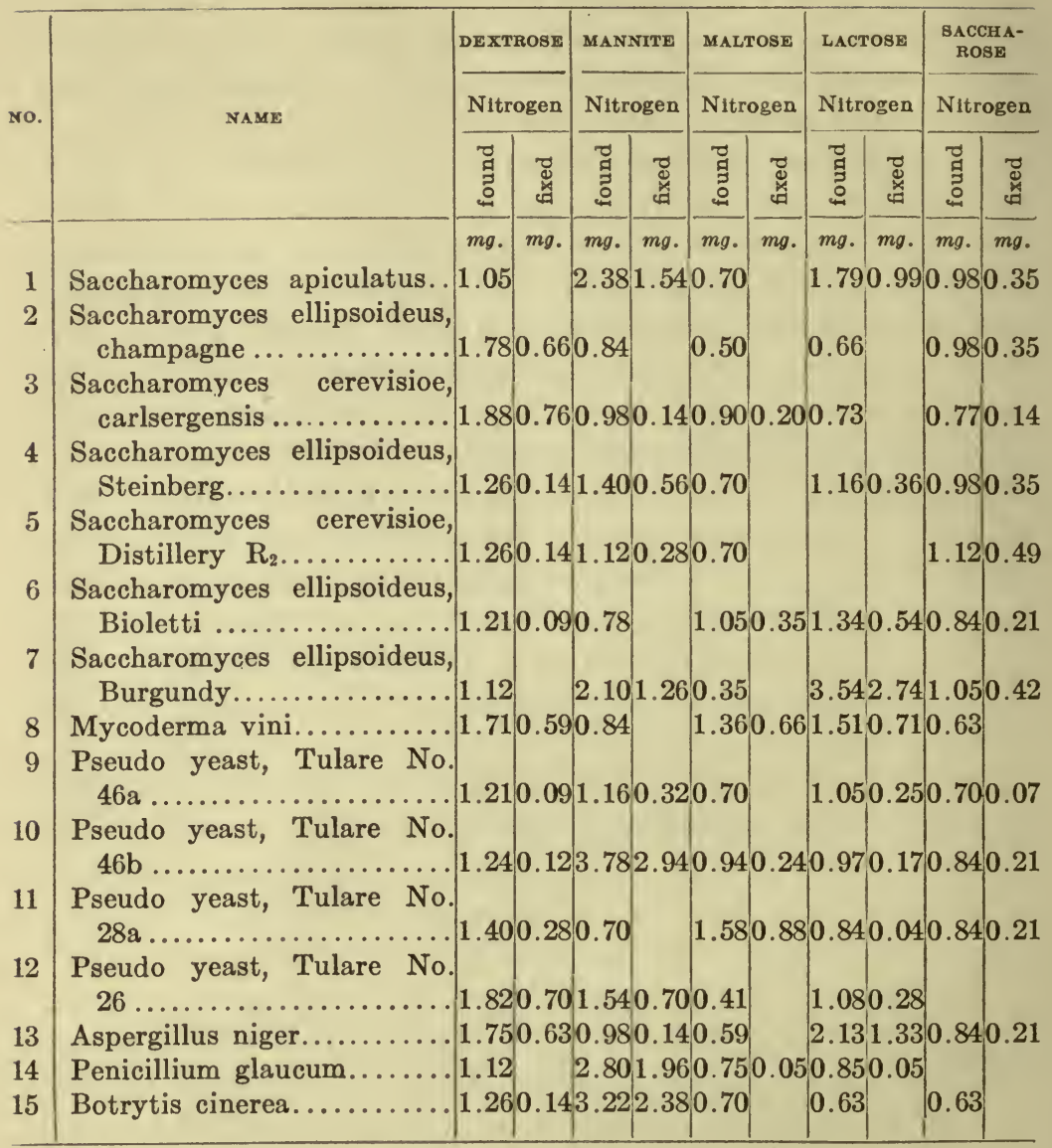

water media as in the tap water media, they are in many cases definite enough to remove any doubt that these organisms are possessed of the power of fixing atmospheric nitrogen, even if amounts below $0.3 \mathrm{mg}$. nitrogen are to be attributed to experimental error which indeed the writer very seriously doubts. There were slight losses of nitrogen from some of the culture solutions which can hardly be explained in any other way than by attributing them to experimental error. It is very striking that organisms which in their natural habitats are accustomed to drawing their nitrogen supply from a plentiful store of that element 
can be made to fix atmospheric nitrogen in nitrogen-poor or nitrogen-free solutions with one of the sugars or mannite as a source of energy. Maltose and saccharose do not seem to be nearly as well suited to the growth and development of the organisms tested as lactose, dextrose and mannite, the last seeming to be the most favorable when the organisms are considered as a whole. The largest fixation of nitrogen was $2.94 \mathrm{mg}$. per gram of mannite fixed by Pseudo-yeast Tulare no. 46b. The next largest 2.74 $\mathrm{mg}$. by the Burgundy wine yeast per gram of lactose and the next largest $2.38 \mathrm{mg}$. per gram mannite by Botrytis cinerea. Several other considerable amounts were fixed by other organisms in mannite and lactose solutions which two seem to be the best suited for the fixation of large amounts of nitrogen in distilled water cultures.

\section{GENERAL DISCUSSION.}

A careful consideration of the data above given brings further confirmation of the work of other investigators to the effect that the power of fixing atmospheric nitrogen is possessed by many of the lower organisms which differ widely in their character. Though the amounts fixed by them, as shown above, are not as large as those fixed by $B$. radicicola in conjunction with the leguminous plants nor yet as large as those fixed by the more vigorous species of the Azotobacter group, they are none the less definite and considerable. To the list of organisms which can fix atmospheric nitrogen as shown by former investigations may now be added the true yeasts and the "pseudo yeasts," besides Botrytis cinerea, an organism whose parasitic nature would seem to have deprived it of any nitrogen fixing power whatever. This in itself is a very interesting and striking fact. The fixation of nitrogen seems to have been made easier for the organisms in tap water solutions than in distilled water solutions owing to the small amounts of combined nitrogen present in the former. The nitrogen fixed would, in many cases, seem to have been of a soluble nature since considerable fixation was often noted in solutions where the growth would not seem to indicate it. The conclusions of Duggar and Knudson $^{1}$ are therefore not supported by the investigations above described. An effort is now being made by the writer to carry

${ }^{1}$ Science, N. S., xxxiii, p. 191, 1911. 
out some experiments on the fixation of nitrogen by fungi similar to those with which Duggar and Knudson worked and it is hoped that the results may be available for publication in the near future.

The objections of Czapek to the work of Puriewitsch and Saida would not seem to be valid in view of the writer's experiments, since the method of nitrogen determination employed as above described has been carefully tested in my laboratory, allows of a close agreement between duplicate series of determinations, and has given most satisfactory results in other phases of microbiological work.

\section{SUMMARY OF RESULTS.}

1. Of eighteen organisms, including yeasts, pseudo yeasts and molds, tested nearly all show a more or less pronounced power of fixing atmospheric nitrogen.

2. Tap water sugar solutions are better suited for nitrogen fixation by the organisms tested than distilled water solutions.

3. Mannite and lactose solutions are far superior to dextrose, saccharose and maltose solutions for these organisms in distilled water, but dextrose is the best in tap water solutions. Maltose is the most unsatisfactory.

4. The highest amount of nitrogen fixed was $2.94 \mathrm{mg}$. per gram of mannite by pseudo yeast Tulare no. $46 \mathrm{~b}$ in distilled water mannite solution.

5. The results of other investigators with reference to the nitrogen fixing powers of Aspergillus niger and Penicillium glaucum are confirmed.

6. Botrytis cinerea, a parasitic fungus, has been found for the first time, so far as the writer is aware, to possess a nitrogen fixing power.

My thanks are due my former assistant, Mr. J. A. McKeen, for valuable assistance in making the nitrogen determinations. 
.

\section{-}

$=$

$-$ 


\section{UNIVERSITY OF CALIFORNIA LIBRARY,
BERKELEY}

\section{THIS BOOK IS DUE \\ STAMPED THE LAST DATE}

Books not returned

$50 \mathrm{c}$ per volume after the third are subject to a fine of demand per volume after the sixth overdue, increasing demand may be renewed if sixth day. Books not in expiration of loan period.

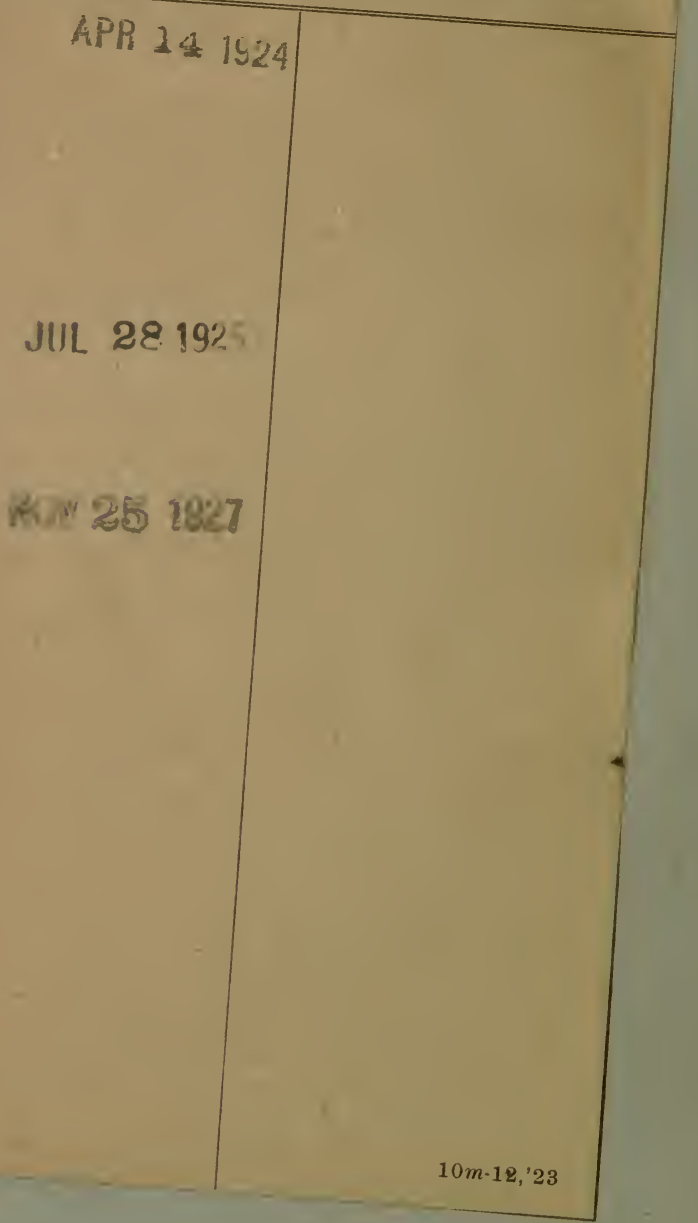


Syracuse, N. Y.

PAT. JAN. 21, 1908

\section{4}

\section{1 \\ 15}

UNIVERSITY OF CALIFORNIA LIBRARY 
